\title{
Evaluation of School Based Assessment Teacher Training Programme
}

\author{
Mohd Azmi Mat Yusoff' ${ }^{1}$ Jamil Ahmad ${ }^{1}$, Azlin Norhaini Mansor ${ }^{1}$, Rahayu Johari ${ }^{1}$, \\ Kamisah Othman ${ }^{1}$, Norlizah Che Hassan² \\ ${ }^{1}$ Faculty of Education, Universiti Kebangsaan Malaysia, Bangi, Malaysia \\ ${ }^{2}$ Faculty of Education, Universiti Putra Malaysia, Serdang, Malaysia \\ Email: azmiwrr6@yahoo.com.my
}

Received 5 March 2016; accepted 17 April 2016; published 20 April 2016

Copyright (C) 2016 by authors and Scientific Research Publishing Inc.

This work is licensed under the Creative Commons Attribution International License (CC BY).

http://creativecommons.org/licenses/by/4.0/

(c) (i) Open Access

\begin{abstract}
This study employed the Kirkpatrick Evaluation Model to assess the reaction of in-service teacher training program on School Based Assessment (SBA) and its contribution towards teacher's learning (knowledge, skills and attitudes). Kirkpatrick evaluation model has four stages, namely the assessments of reaction, learning (knowledge, skills and attitudes), behavioural and outcomes. This study will discuss the first two stages of assessments that is reaction and learning (knowledge, skills and attitudes). This quantitative survey study used self-developed questionnaires, involving 1200 primary school teachers who had attended the in-service training programme. The respondents were selected randomly from the state of Selangor, Malaysia. The findings of the assessment on reaction which included five sub variables, was on average at a high level. Based on regression analysis: 1) three independent variables (reaction) contributed 21.7 percent to the variances of dependent variables (knowledge); 2) three independent variables (reaction) contributed 19.4 percent to the variances of dependent variable (skills); and 3) three independent variables (reaction) contributed $\mathbf{1 7 . 2 0}$ percent to the variance of dependent variable (attitudes). These findings suggest that the SBA teacher training program should be continued with strategic improvements to alleviate teachers' knowledge, skills and attitudes to better improved the implementation of SBA program.
\end{abstract}

\section{Keywords}

Reaction Evaluation, In-Service, Teacher Training, School Based Assessment, Kirkpatrick Model

\section{Introduction}

When the Standard Curriculum for Primary Schools (KSSR) was introduced in 2011, School Based Assessment

How to cite this paper: Yusoff, M. A. M., Ahmad, J., Mansor, A. N., Johari, R., Othman, K., \& Hassan, N. C. (2016). Evaluation of School Based Assessment Teacher Training Programme. Creative Education, 7, 627-638.

http://dx.doi.org/10.4236/ce.2016.74065 
(SBA) for primary schools was implemented to replace the Primary School Assessment Test (PSAT). This change was made to improve on the national assessment system with more emphasis on school based assessment. Thus, the exposure of the implementation and practice of SBA through relevant in-service teacher training program is in line with the aspirations of the nation to strengthen human capital with the right knowledge, skills and attitudes. The program is also aimed at making teachers professionals who are able to disseminate new knowledge and information to students. Thus, this program is deemed important because training is the single and most important factor that can help to improve the quality of service (John, 1989). Effective in-service training program can help an organization to achieve its goals (Buckley \& Caple, 1992).

This study employed the Kirkpatrick Evaluation Model which has four stages, namely the assessments of reaction, learning (knowledge, skills and attitudes), behaviour and outcomes (Kirkpatrick, 1959). However, this study only used two stages of assessment; reaction and learning (knowledge, skills and attitudes). The assessment of reaction was ranked first in the Kirkpatrick Evaluation Model. This level of evaluation is important because it can affect the training program. This stage does not indicate any outcome as it does not measure the mastery of learning (knowledge, skills and attitudes), behaviour and results. However, a positive reaction is very important in the evaluation exercise, even though it does not necessarily guarantee the enhancement of learning (knowledge, skills and attitude) as negative reaction will definitely affect the achievement of learning (Kirkpatrick, 2000). Therefore, it is important to assess this program in terms of the participants' reactions and its contribution towards learning (knowledge, skills and attitudes).

\section{Literature Review}

Moidunny (2009), Hashim et al. (2007), and Withers (2000) stated that the physical facilities provided during training were satisfactory. Physical facilities are important to ensure comfort during teacher training. This indicates that teachers have a positive reaction to the SBA in-service training program. Physical facilities such as air conditioners, fans, chairs, tables, Liquid-Crystal Display (LCD) screens, whiteboards and stationery can help alleviate the effectiveness of the SBA training. Materials or resources provided during the SBA training can help and benefit teachers in implementing SBA in schools (Mohd Asari, 2013). Studies shown that majority of participants in a in-service training program are satisfied with the materials provided during training (Moidunny, 2009; Md. Noor, 2003). The use of appropriate lessons also improves the effectiveness of the teaching and learning process in a training institution (Hashim et al. 2007).

Ibrahim (1992) stated that most of the teaching staff for the in-service training was not provided with adequate training to operate the program, which led to poor quality of training to be benefitted by teachers. In addition, the in-service training lectures, briefings and courses restricted to two-way communications needed to be modified, and as most of the trainings mainly concerned with theoretical training, real problems that arise in the process of implementing SBA was side lined (Rodzi, 2012). MC or facilitators should engage participants in the learning process and seek the views and ideas of the participants regarding the topics to be learnt (Knowles, 1980). There are a handful of MC/facilitators who deliver the training in the form of lectures, briefings and courses restricted to two-way communications, which calls for modification so that the process of teaching and learning through the implementation of the SBA can be adhered to and parallel (Rodzi, 2012). A few studies revealed that teachers give a satisfactory response on the training content (Moidunny, 2009; EPRD, 2006; Hassan et al., 2006; Md. Noor, 2003). Teachers also expressed that trainings need to be done more frequently (Mohd Asari, 2013).

Learning is a process of change that involves the increased ability to perform something in relation to one's interests, attitudes and values. This change comes through one's experience and training (Abdul Hamid et al., 2004). The knowledge gained through training will help teachers to become more proficient in assessing students' work in the classroom. Those responsible for the in-service teacher training programs should consider a more effective way to provide trainings for teachers, especially those involving large-scale changes. It would be more meaningful if teachers are provided with a comprehensive knowledge of SBA (Jaba, 2013).

Teachers' skills are important in the implementation of SBA (Mohd Asari, 2013). Teachers' skills can be improved through trainings provided. With proper trainings, useful information will be disseminated, teachers' capabilities will be enhanced and they will be more efficient in managing and handling the SBA in accordance with the procedures dictated by the MOE. Without proper skills, teachers will not be able to implement the SBA as planned. This means that the credibility of the SBA may be improved with proper implementation of trainings 
to enhance the high level of readiness in terms of knowledge, skills and attitudes among teachers who perceive the program as a classroom's main interest and needs (Jaba, 2013). This suggests that effective training will have a positive impact on the improvement of reaction and contributes to the improvement of learning (knowledge, skills and attitudes) Bramley (1996), Kirkpatrick (1975, 1994, 1996, 2000), McNamara (1998), Reeves (1994). Razali (2006) also found a significant relationship between the LDP and the effectiveness of teaching.

\section{Problem Statement}

Realising that the SBA is still at its infancy, and to ensure the smooth implementation of the program, the Education Ministry through the State Education Departments, District Education Offices and all schools need to work hand in hand to provide proper training to teachers on how to implement the SBA (Examination Board, 2012) and the training should be evaluated. There are some setbacks detected in terms of management and implementation of the training program organised by the Education Ministry, for instance the lack of consistency in the training programs organized by the different departments such as the Teacher Education Department, the State Education Departments, District Education Offices and schools. Apart from that, in-service teacher training programs cannot be conducted properly because of the prevailing constraints in terms of physical facilities and teaching resources. The in-service teacher training program carried out must be in accordance with and relevant to the needs and requirements of the MOE, i.e. the training should not be general in nature but focused on the subject matter (Mansor, 2009).

The communication of information relating to SBA through the ITTP begins with the Ministry of Education, which passes down the information to the different states through the State Education Departments which would further disseminate the information to all the schools through the District Education Offices. The various stages of delivering the information resulted in a watered-down program. Main Coaches (MC) or better known as Jurulatih Utama (JU) first received their trainings from the National Coaches (NC) or Jurulatih Kebangsaan (JK) for five days, normally from 8 am until $10 \mathrm{pm}$. But the information submitted by the MC to teachers through the ITTP took only four days, from 8 am to $5.00 \mathrm{pm}$. The teachers who received the training will deliver the information to the rest of the teachers at a school through the in house training program in a much shorter time (Rodzi, 2012). Thus, the quality of the delivery of knowledge and skills is significantly reduced. ITP should be practiced-oriented. In-service training lectures, briefings and courses restricted to two-way communications needed to be modified so that the style of teaching and learners' learning styles through the implementation of SBA will always be parallel (Rodzi, 2012). The widely used method of giving lectures during the in-service training programs takes the interest out of the attendees. As most trainings focused mainly on the content and theories of lessons, real problems that arise from the implementation of the SBA escaped unnoticed.

The MC conducting the in-service training program also needs to be supervised as not all MC have the extensive experience in handling the new program. Thus the question is whether they have the proper expertise needed to train teachers to handle SBA, as they themselves were only recently involved with the SBA program. As such, the assessment of the reaction in this study will be able to identify to what extent the MC are able to handle this program. Ibrahim (1992) stated that most of the teaching staff of ITP is not given adequate training to operate the program, which leads to poor quality of training to be benefited by teachers.

Thus, the purpose of this study is to assess the reaction of teachers involved in the SBA in-service teacher training program run by the Ministry of Education Malaysia for primary school teachers and its influence towards learning (knowledge, skills and attitudes).

\section{Research Questions}

The research questions of this study are:

a) What is the level of reaction of the teachers who participated in the SBA in-service training program for the constructs of physical facilities, instructional materials, teaching materials, presentations of MC/facilitators and the general content?

b) Is there a contribution of the independent variables (reaction) to teachers' knowledge after attending the SBA in-service training program?

c) Is there a contribution of the independent variables (reaction) to teachers' skills after attending the SBA in-service training program?

d) Is there a contribution of the independent variables (reaction) to teachers' attitudes after attending the SBA in-service training program? 
Hypotheses of the study

a) There is no significant contribution of the independent variables (reaction) to teachers' knowledge after attending the SBA in-service training program.

b) There is no significant contribution of the independent variables (reaction) to teachers' skills after attending the SBA in-service training program.

c) There is no significant contribution of the independent variables (reaction) to teachers' after attending the SBA in-service training program.

\section{Research Methodology}

This evaluation research survey employs the Kirkpatrick Evaluation Model which has four stages, namely the evaluations of reaction, learning (knowledge, skills and attitudes) behaviour and outcomes (Kirkpatrick, 1959). In this study, only two stages will be reported; evaluations of reaction and of learning, under the subcategories of knowledge, skills and attitudes.

A questionnaire was developed and distributed to 1200 randomly selected primary school teachers in the state of Selangor. They represented 60 percent from all teachers in Selangor who had attended the in-service training programme in 2012. Majority of the respondents were female (83.8\%), and only 195 males (16.3\%). Almost all respondents (75\%) had been teaching as trained teachers for more than 5 years. The majority of samples involved were Malay Language teachers, followed by teachers of Mathematics, English and Science teachers. These four subjects are core subjects in primary schools.

The questionnaire used in this study was developed based on the objectives, constructs readings of the SBA manual (Examination Board, 2012), and previous studies (Moidunny, 2009; Chan, 2004). The questionnaire used a five-point Likert scale, and the overall Cronbach Alpha value for the questionnaire items was between 0.939 and 0.985 . There are 149 items in the questionnaire.

To analyse the descriptive data, mean, percentage and standard deviation were used. The interpretation of the mean scores to determine the degree of the respondents' reaction is as follows; the mean score of 1.00 to 2.33, is interpreted as low, a mean score of 2.34 to 3.66 is interpreted as average, and a mean score of 3.67 to 5.00 , is interpreted as high.

For inferential analysis, the multiple regression (Stepwise) was used to specify a linear relationship between several independent variables and the dependent variable (Konting, 2002). Before the multiple regression analysis was performed, the researchers ensured and verified the normal distribution and linearity of the scores of questionnaires. This was done by means of residuals scatter plot and normal regression plot. This step is important because multiple regression analysis assumes that the distribution of scores is normal and linear (Ahmad, 2002). Researchers also ensured that the assumptions of multiple regression such as sample size, normality, outliers, linearity, multicollinearity and singularity, homoscedasticity, and independence of residuals were observed (Pallant, 2010).

\section{Findings}

\section{Teachers' Reaction on the SBA In-Service Training Program}

The assessment of teachers' reaction on the SBA in-service training program on PBS included the constructs of physical facilities, instructional materials, teaching materials, presentations of $\mathrm{MC} /$ facilitators and general content. The results of this analysis will answer the first research question. The analysis of the teachers' reaction is shown in Table 1.

Table 1. Frequency and percentage for mean score and level of reaction.

\begin{tabular}{|c|c|c|c|c|c|c|c|c|c|}
\hline \multirow{3}{*}{ Constructs of evaluation of reaction } & \multicolumn{6}{|c|}{ Frequency and percentages } & \multirow{3}{*}{ Mean score } & \multirow{3}{*}{ SD } & \multirow{3}{*}{ Level } \\
\hline & \multicolumn{2}{|c|}{ Low level } & \multicolumn{2}{|c|}{ Medium level } & \multicolumn{2}{|c|}{ High level } & & & \\
\hline & $\mathrm{F}$ & $\%$ & $\mathrm{~F}$ & $\%$ & $\mathrm{~F}$ & $\%$ & & & \\
\hline Physical facilities & 5 & 0.4 & 313 & 26.1 & 882 & 73.5 & 3.86 & 0.50 & High \\
\hline Instructional materials & 18 & 1.5 & 285 & 23.8 & 897 & 74.8 & 3.82 & 0.51 & High \\
\hline Teaching materials & 13 & 1.1 & 330 & 27.5 & 857 & 71.4 & 3.80 & 0.49 & High \\
\hline Presentations by JU/facilitators & 7 & 0.6 & 409 & 34.1 & 784 & 65.3 & 3.79 & 0.45 & High \\
\hline General content & 6 & 0.5 & 284 & 23.7 & 910 & 75.8 & 3.83 & 0.43 & High \\
\hline
\end{tabular}


Table 1 shows the level of evaluation on teachers' reaction to physical facilities is at a high level (mean = 3.86, $\mathrm{SD}=0.50)$. Similarly, the reaction of teachers are to be at a level high for learning $(\mathrm{mean}=3.82, \mathrm{SD}=$ 0.51 ), general content $($ mean $=3.83, \mathrm{SD}=0.43$ ), teaching materials (mean $=3.80, \mathrm{SD}=0.49$ ) and presentations by JU/facilitator (mean $=3.79$, SD $=0.45$ ). All constructs above showed a high level, which indicates that teachers have positive reactions and are satisfied with the SBA in-service training program.

Independent Variables (Reaction) Contributing to Teachers' Knowledge after the SBA In-Service Training Program

Stepwise multiple regression analysis was conducted to determine and identify the relationship and the contribution of the variance of independent variables (reaction) to teachers' knowledge after attending the SBA in-service training program as described in the null hypothesis (no.1).

Ho1: There is no significant contribution of independent variables (reaction) to teachers' knowledge after attending the SBA in-service training program.

Therefore, multiple regression was performed between the mean score of independent variables involving five independent variables, namely (1) physical facilities, (2) instructional materials, (3) learning materials, (4) presentations by JU/ facilitator, (5) general content with reaction of the mean score of knowledge (the dependent variable).

The assumed normality can be seen in the normal probability plots. If the actual data distribution is normal, the line representing the actual data matches or nearly matches the diagonal line (Appendix A1 and Appendix A2). The researchers also looked at the correlation between independent variables with independent variables to determine whether there is multicollinearity (Appendix A3). To overcome multicollinearity in multiple regression analysis, researchers used stepwise multiple regression analysis (Hair et al., 2006).

In this section the results of multiple regression analysis involved five independent variables (reaction) on dependent variables, namely the level of knowledge of the teachers who attended the training in SBA. Three of the five independent variables showed significant correlations and contributions $(p<0.05)$ to the level of teachers' knowledge. The independent variables were general content, physical facilities and learning materials as shown in Table 2 and Table 3.

Table 2 and Table 3 indicate that in general, the three variables, namely the general content, physical facilities and learning materials accounted for 21.7 per cent $\left(r^{2}=0.217\right)$ on the changes in the level of variance teachers' knowledge. Analysis of variance revealed that the $\mathrm{F}_{(3,1181)}=109,775$ at a significant level of $p<0.05$.

Comparing the three variants, the main and highest predictor contributed 17.60 percent to the level of teachers' knowledge was general content $(\beta=0.244, \mathrm{t}=6916$ and $p<0.05)$. This suggests that when scores of general content among teachers who attended the SBA in-service training increased by one unit, the level of teachers' knowledge also increased by 0.244 units. The second highest predictor contributed 2.70 percent to the level of teachers' knowledge was the physical facilities $(\beta=0.146, t=4,896$ and $p<0.05)$. This suggests when the score of physical facilities among teachers who attended the SBA in-service training PBS increased by one unit, then the level of teachers' knowledge increased by 0.146 units. The third-highest predictor contributed 1.40 per cent to the level teachers' knowledge was learning materials ( $\Omega=0.168, \mathrm{t}=4655$ and $p<0.05$ ). When the score of learning materials among teachers who attended the SBA in-service training program increased by one unit, the level of teachers' knowledge increased by 0.168 units.

Table 2. Multiple regression analysis (stepwise) for independent variables (reaction) on the contributions to teachers' knowledge after SBA in-service training program.

\begin{tabular}{|c|c|c|c|c|c|c|}
\hline Variables (X) & $\mathrm{B}$ & Beta $(\beta)$ & t value & Sig.-t & $\mathrm{R}^{2}$ & Contribution (\%) \\
\hline General content & 0.289 & 0.244 & 6.919 & 0.000 & 0.176 & 17.60 \\
\hline Physical facilities & 0.149 & 0.146 & 4.896 & 0.000 & 0.203 & 2.70 \\
\hline Learning materials & 0.175 & 0.168 & 4.655 & 0.000 & 0.217 & 1.40 \\
\hline \multirow[t]{5}{*}{ Constant } & 1.134 & & 8.594 & 0.000 & & \\
\hline & \multicolumn{3}{|c|}{$\mathrm{R}$} & & \multicolumn{2}{|r|}{0.466} \\
\hline & \multicolumn{2}{|c|}{ R Squared } & & & \multicolumn{2}{|r|}{0.217} \\
\hline & \multicolumn{2}{|c|}{ Adjusted R Squared } & & & \multicolumn{2}{|r|}{0.215} \\
\hline & \multicolumn{2}{|c|}{ Standard Error } & & & \multicolumn{2}{|r|}{0.445} \\
\hline
\end{tabular}


Table 3. Analysis of variance (dependent variable : Teachers’ knowledge).

\begin{tabular}{cccccc}
\hline Model & Sum of squares & df & Mean square & F & Sig. (p) \\
\hline Regression & 65.000 & 3 & 21.667 & 109.411 & 0.000 \\
Residual & 233.875 & 1181 & 0.198 & & \\
Total & 298.876 & 1184 & & & \\
\hline
\end{tabular}

The variables that predict the overall level of teachers' knowledge consists of three independent variables. The findings from the regression equation can be written as follows:

$$
\mathrm{Y}=1.134+0.289 \mathrm{X}_{1}+0.149 \mathrm{X}_{2}+0.175 \mathrm{X}_{3}+0.446
$$

whereas;

$\mathrm{Y}=$ Level of Teachers' Knowledge

$\mathrm{X}_{1}=$ General Content

$\mathrm{X}_{2}=$ Physical Facilities

$\mathrm{X}_{3}=$ Learning Materials

Constant $=1.134$

Error $=0.445$

Based on the regression equation above, the first null hypothesis (Ho.1) was rejected. Stepwise regression analysis revealed three independent variables; i.e. the general content, physical facilities and learning materials correlated and contributed to the knowledge of the teachers who attended the training in SBA.

Independent Variables (Reaction) Contributing to Teachers' Skills after the SBA In-Service Training Program

Multiple regression analysis (stepwise) was conducted to determine and identify the relationship and the contribution of the variance of independent variables (reaction) on teachers' skills after participating in the SBA in-service training program as described in the second null hypothesis (Ho.2).

Ho2: There is no significant contribution of independent variables (reaction) to teachers' skills after attending the SBA in-service training program.

Multiple regression was performed between the mean scores of skills (dependent variable) with reaction (independent variables) involving five independent variables, namely (1) physical facilities, (2) instructional materials, (3) learning materials, (4) presentations by MC/Facilitator, (5) general content.

The assumed normality can be seen in the normal probability plots. If the actual data distribution is normal, the line representing the actual data matches or nearly matches the diagonal line (Appendix A4 and Appendix A5). The researchers also looked at the correlation between independent variables with independent variables to determine whether there is multicollinearity (Appendix A6). To overcome multicollinearity in multiple regression analysis, researchers used stepwise multiple regression analysis (Hair et al., 2006).

The results of multiple regression analysis involved five independent variables (reaction) on the dependent variable (skills) of teachers' skills who attended the training in SBA. Three of the five independent variables showed significant correlations and contributions $(p<0.05)$ to the level of teachers' skills. The independent variables were general content, physical facilities and learning materials as shown in Table 4 and Table 5 .

Table 4 and Table 5 reveal that overall, the three predictor variables (variants) of the five variables, namely the general content, physical facilities and learning materials accounted for 19.4 per cent (r2 =0.194) on the changes in teachers' skills. The analysis of variance revealed that the $\mathrm{F}_{(3,1181)}=94,592$ at a significant level of $p$ $<0.05$.

Comparing the three variants, the main and the highest predictor contributing 16.60 percent to teachers' skill is general content $(\beta=0.266, t=7438$ and $p<0.05)$. This situation shows when scores of general content among teachers who attended the SBA in-service training program increased by one unit, teachers' skill increased by 0.266 units. The second highest predictor contributed 1.90 percent to the level of teachers' skills is the physical facilities ( $\beta=0.123, \mathrm{t}=4.090$ and $p<0.05$ ). This means when the score of physical facilities among teachers who attended the SBA in-service training program increased by one unit, the level of teachers' skill increased by 0.123 units. The third highest predictor contributing 0.90 per cent of the level of teachers' skill is learning materials ( $\beta=0131, \mathrm{t}=3,584$ and $p<0.05$ ). This suggests when the score of learning materials among teachers who attended the SBA in-service training program increased by one unit, the skill of teachers increased by 0.131 units. 
Table 4. Multiple regression analysis (stepwise) for independent variables (reaction) on the contribution to teachers' skills after the SBA in-service training program.

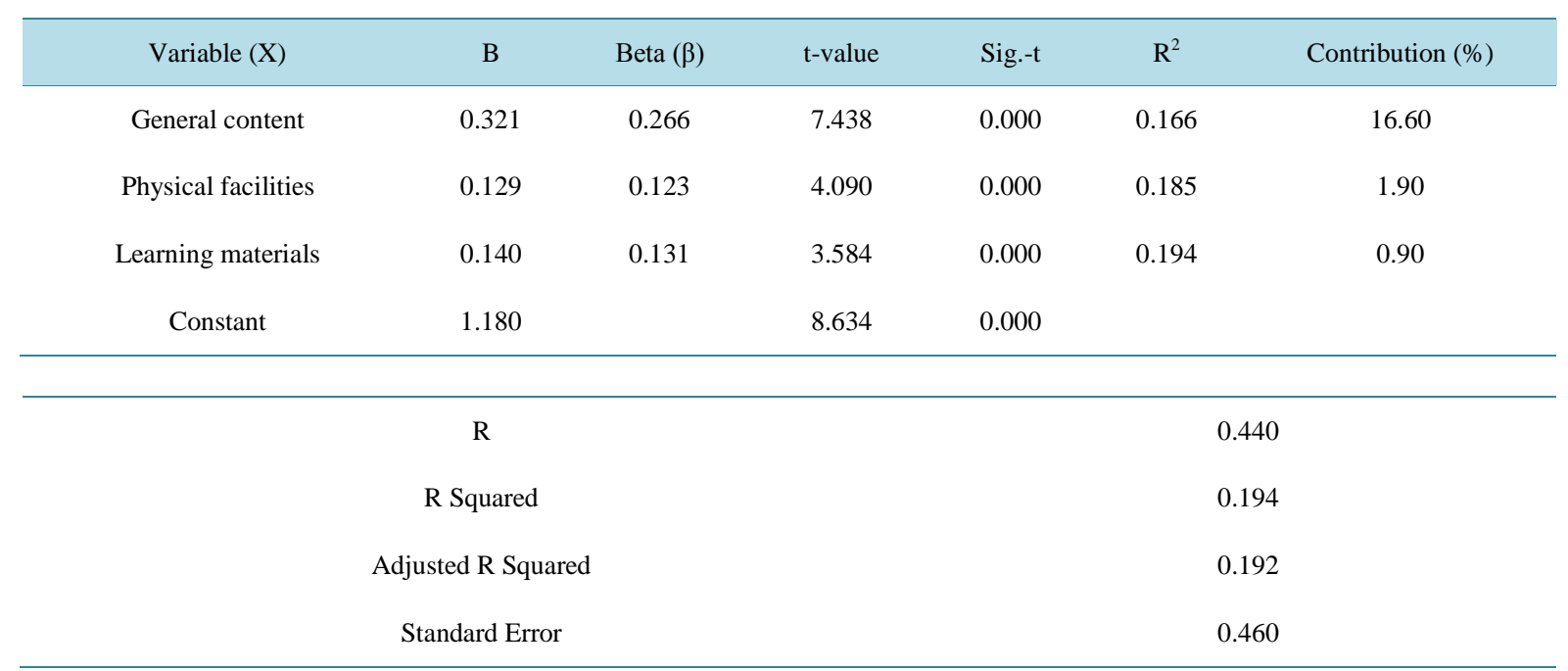

Table 5. Analysis of variance (dependent variable: Teachers’ skills).

\begin{tabular}{cccccc}
\hline Model & Sum of squares & df & Mean square & F & Sig. (p) \\
Regression & 60.223 & 3 & 20.074 & 94.592 & 0.000 \\
Residual & 250.631 & 1181 & 0.212 & & \\
Total & 310.854 & 1184 & & & \\
\hline
\end{tabular}

The variables that predict the overall level of teachers' skill consists of three independent variables. The findings from the regression equation can be written as follows:

$$
Y=1.180+0.321 X_{1}+0.129 X_{2}+0.140 X_{3}+0.460
$$

whereas;

$\mathrm{Y}=$ Level of Teachers' skills

$\mathrm{X}_{1}=$ General Content

$\mathrm{X}_{2}=$ Physical Facilities

$\mathrm{X}_{3}=$ Learning Materials

Constant $=1.180$

Error $=0.460$

Based on the regression equation above, the second null hypothesis (Ho.2) was rejected. The stepwise regression analysis revealed that three independent variables; i.e. the general content, physical facilities and learning materials correlated and contributed to the skill of teachers who attended the SBA training program.

Independent Variables (Reaction) Contributing to Teachers' Attitude after the SBA In-Service Training Program

Multiple regression analysis (stepwise) was conducted to determine and identify the relationship and the contribution of the variance of independent variables (reaction) on the attitudes of teachers after participating in the SBA in-service training program as described in the null hypothesis (Ho.3).

Ho3: There is no significant contribution of independent variables (reaction) to the attitude of the teachers after attending the SBA in-service training program.

Multiple regression was performed between the mean scores of attitude (dependent variable) with reaction (independent variables) involving five independent variable physical facilities, instructional materials, learning materials, presentation by MC/facilitators and general content. 
The assumed normality can be seen in the normal probability plots. If the actual data distribution is normal, the line representing the actual data matches or nearly matches the diagonal line (Appendix A7 and Appendix A8). The researchers also looked at the correlation between independent variables with independent variables to determine whether there is multicollinearity (Appendix A9). To overcome multicollinearity in multiple regression analysis, researchers used stepwise multiple regression analysis (Hair et al., 2006).

The results of multiple regression analysis involved five independent variables (reaction) on the dependent variable (attitude) of the level of teachers' attitudes who attended the SBA in-service training program. Three of the five independent variables showed significant correlations and contributions $(p<0.05)$ on the level of teachers' attitudes. The independent variables were general content, instructional materials and learning materials as shown in Table 6 and Table 7.

Table 6 and Table 7 show that in overall the three variables (variants) of the five variables, namely the general content, teaching materials and learning materials accounted for 17.20 per cent $(\mathrm{r} 2=0172)$ on the changes of teachers' attitudes. The analysis of variance revealed that the $\mathrm{F}_{(3,1180)}=81.982$ at a significant level of $p<0.05$.

Comparing the three variants, the main and the highest predictor contributing 15.40 percent to the level of attitude is general content $(\beta=0.239, t=6.005$ and $p<0.05$ ). This suggests when scores of general content among teachers who attended the SBA in-service training program increased by one unit, the level of teachers' attitude increased by 0.239 units. The second highest predictor contributed 1.40 percent to the level of attitude is the instructional materials $(B=0.126, \mathrm{t}=3.109$ and $p<0.05)$. When the score of the instructional materials among teachers who attended the SBA in-service training program increased by one unit, then the level of teachers' attitude increased by 0.126 units. The third-highest predictor of 12.40 per cent contributing to the level of attitude is learning materials ( $\beta=0.097, t=2.482$ and $p<0.05$ ). This suggests when the score of learning materials among teachers who attended the SBA in-service training program increased by one unit, the level of teachers' attitude increased by 0.097 units.

Table 6. Multiple regression analysis (stepwise) for independent variables (reaction) on the contributions to teachers' attitude after the SBA in-service training program.

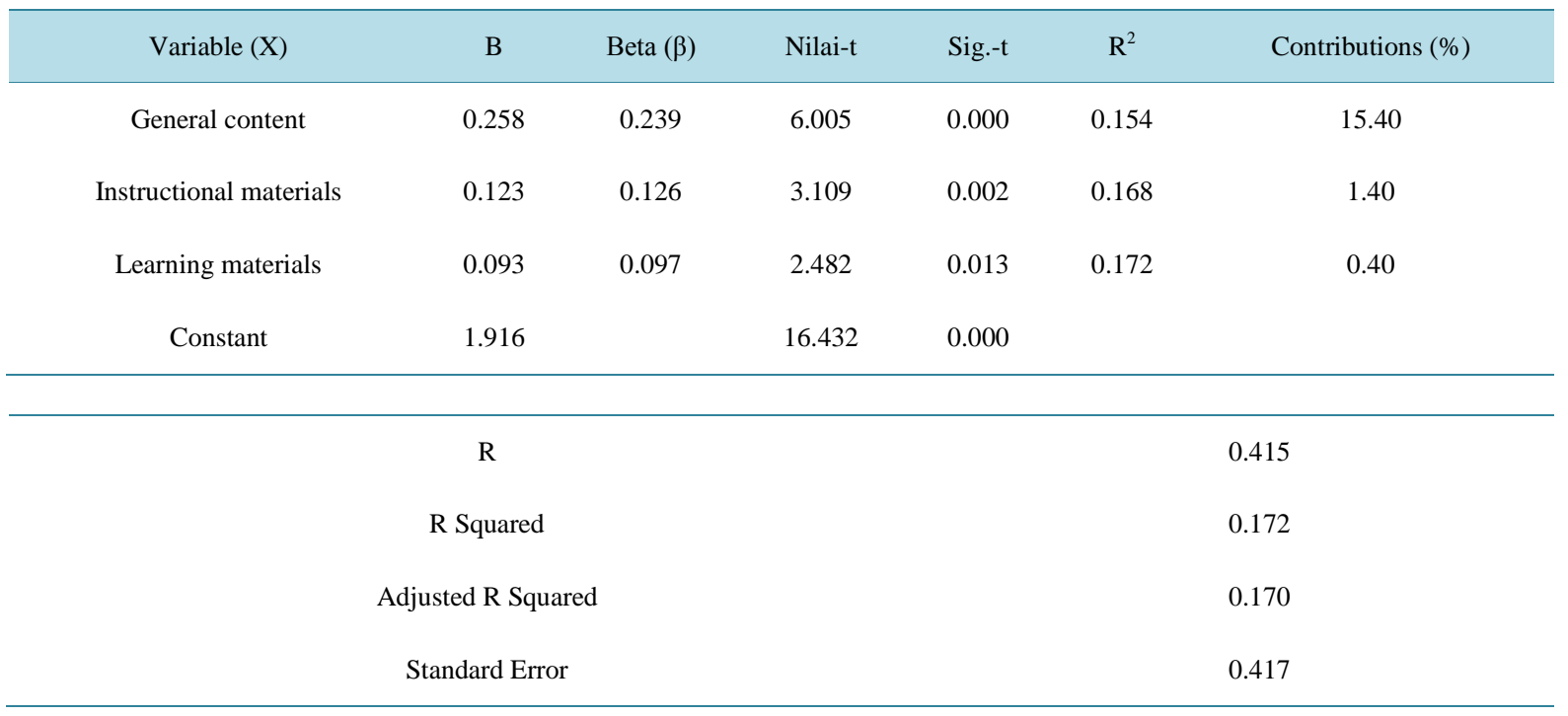

Table 7. Analysis of variance (dependent variable: Teachers’ attitude).

\begin{tabular}{ccccc}
\hline Model & Sum of squares & df & Mean square & F \\
Regression & 42.907 & 3 & 14.302 & 81.982 \\
Residual & 205.858 & 1180 & 0.174 \\
Total & 248.765 & 1183 & & \\
\hline
\end{tabular}


The variables that predict the overall level of attitude consists of three independent variables. The findings from the regression equation can be written as follows:

$$
\mathrm{Y}=1.916+0.258 \mathrm{X}_{1}+0.123 \mathrm{X}_{2}+0.093 \mathrm{X}_{3}+0.417
$$

whereas,

$\mathrm{Y}=$ Level of Teachers' Attitude

$\mathrm{X}_{1}=$ General Content

$\mathrm{X}_{2}=$ Instructional Materials

$\mathrm{X}_{3}=$ Learning Materials

Constant $=1.916$

Error $=0.417$

Based on the regression equation above, the third null hypothesis (Ho.3) was rejected. The stepwise regression analysis revealed that three independent variables; i.e. general content, instructional materials and learning materials correlated and contributed to teachers' attitude who attended the SBA in-service training program.

\section{Discussions}

\section{The Assessment of Reaction of Teachers in the SBA In-Service Training Program}

Based on the findings, the score mean of the assessment on reaction as a whole is at a high level. This indicates that the SBA in-service training program has achieved its goal. This suggests that teachers have a positive reaction to the SBA in-service training program. The assessment of reaction to physical facilities provided by the organizers as a whole is satisfactory (73.5\%). This is also consistent with the previous studies (Moidunny, 2009; Hashim et al., 2007; Withers, 2000) which found that physical facilities provided during the in-service training was satisfactory. Physical facilities are imminent in ensuring participants' comfort during in-service training.

The overall assessment on reaction to learning materials during the SBA training program is satisfactory (74.8\%). This results support the findings by Suriana (2013) which stated that the materials provided during training PBS can assist and benefit teachers implementing the SBA in school. The overall assessment on reaction to teaching materials used by MC/facilitator during the SBA training as a whole is satisfactory $(71.4 \%)$. The findings of this study support the findings by Moidunny (2009) and Md. Noor (2003) which stated that the majority of participants were satisfied with the materials provided during training. The findings by Hashim et al. (2007) are also in line with these findings, stating that the use of appropriate teaching materials can help the effectiveness of the teaching and learning process of a training institution.

The evaluation of reaction on the training delivery by MC/facilitator during the SBA in-service training as a whole is satisfactory (65.3\%). The finding is consistent with the findings by Moidunny (2009), Hassan et al. (2006) and Md. Noor (2003) in which the trainees are satisfied with the training delivery of MC/facilitators, and most of the participants are satisfied with the knowledge, skills and teaching delivered by the JU/facilitator. The assessment of reaction on the general content delivered during the SBA in-service training as a whole is satisfactory (75.8\%).

Independent Variables (Reaction) Contributing to Teachers' Knowledge after the SBA In-Service Training

The multiple regression analysis (Stepwise) was conducted involving five independent variables (reaction) on the dependent variable, i.e. teachers' knowledge after attending the SBA in-service training. The five independent variables are physical facilities, instructional materials, teaching materials, the main coaches/facilitators and general content. Three of the five independent variables showed significant correlations and contributions $(p<$ 0.05 ) on the level of knowledge of teachers. The general content, physical facilities and learning materials accounted for 21.70 per cent of the change in the level of teachers' knowledge. This indicates that effective training will have a positive impact on the assessment of reaction and contributes to the improvement of learning in terms of knowledge, skills and attitudes (Bramley, 1996; Kirkpatrick, 2000; McNamara, 1998; Reeves, 1994), teachers' behaviours and work performance. Similarly, Razali (2006) found a significant relationship between the in-service training to teachers' effectiveness in teaching.

Comparing the three variants, the main and the highest predictor contributing 17.60 percent to the level of knowledge was general content. This implies that when the general content provided is of better quality and more effective, it will increase the teachers'. The second highest predictor contributing 2.7 percent to the level 
of knowledge is physical facilities. The third highest predictor contributing 1.4 percent to the level of knowledge is learning materials. Learning is a process of change that involves the improved ability for an act or a job in relation to one's interests, attitudes and values. Experience and training contributed to this change (Abdul Hamid et al., 2004).

The knowledge gained through training will help teachers to become more proficient in assessing students' work in the classroom. Those in charge of the in-service teacher training programs should consider a more effective approach in providing in-service trainings for teachers, especially those involving large-scale changes. It is only appropriate that teachers are provided with a comprehensive knowledge of SBA (Jaba, 2013).

Independent Variables (Reaction) Contributing to Teachers' Skills after the SBA In-Service Training

The results of multiple regression analysis (Stepwise) involved five independent variables (reaction) on the dependent variable of teachers' skills after participating in the SBA in-service training. The five independent variables were the physical facilities, instructional materials, teaching materials, the main coaches/facilitators and general content. Three of the five independent variables showed significant correlations and contributions (p $<0.05$ ) to teachers' skills. The general content, physical facilities and instructional materials contributed 19:40 per cent to teachers' skills. Comparing the three variants, the main and the highest predictor contributing 16.60 percent to teachers' skills is the general content. This implies that when the general content provided is of better quality and more effective for the teachers attending the SBA in-service training, it will lead to an increased level of skills. The second highest predictor contributed 1.90 percent to the level of skills is the physical facilities. The third-highest predictor of contributing 0.9 percent to the level of skills is the learning materials. This situation shows that the learning materials made available to teachers who attend the SBA in-service training will affect their teaching skills.

This implies that the skill of the teacher is the most important factor in the performance of SBA (Mohd Asari, 2013). High-level skills can be improved through proper training of in-service teachers. In-service trainings will provide useful information, enhance teachers' capability to be more efficient in managing and operating of the SBA in accordance with the procedures outlined by the MOE. Without proper skills, teachers will not be able to implement the SBA as planned.

\section{Independent Variables (Reaction) Contributing to the Change of Teachers' Attitude after the SBA In-Service Training}

The results of multiple regression analysis (Stepwise) involved five independent variables (reaction) on the dependent variable of teachers' attitudes after attending the SBA in-service training. The five independent variables were the physical facilities, instructional materials, learning materials, MC/facilitators and the general content. Three of the five independent variables showed significant correlations and contributions $(p<0.05)$ to the level of teachers' attitudes. The independent variables of general content, instructional materials and learning materials contributed 17.20 percent to the changes in teachers' attitude. Comparing the three variants, the main and the highest predictor contributing 15.40 percent to the level of teachers' attitude is general content. This suggests that an effectively designed public content for the SBA in-service training will increase teachers' positive attitudes. The second highest variant contributing 1.40 per cent to the level of attitude is the instructional materials. The third highest predictor contributed 0.004 percent to the level of attitude is learning materials.

This indicates that the credibility of SBA can be improved with proper training to help enhance the level of readiness in terms of knowledge, skills and attitudes among teachers who regard SBA as the main interests and needs in the classroom (Jaba, 2013).

\section{Conclusion}

The findings of this study suggest that the program should be continued with some improvements so teachers can improve on their knowledge, skills and attitudes to effectively implement the school based assessments program. For future studies, we would suggest involving more teachers or teacher trainees in other states throughout Malaysia so that the findings can be generalized to a wider population. We would also suggest for future researchers to use different statistical analysis like Path analysis to identify the variables that affect directly or indirectly the (performance) after attending SBA in-service training.

\section{References}

Abdul Hamid, M. A., Atoma, P., Othman, M. F., \& Markom, M. N. (2004). Andragogy-Teaching Adults to Learn. Bentong PTS Publications \& Distributors Sdn. Bhd. 
Ahmad, J. (2002). Nurturing a Research Culture among School Teachers. An Assessment. Ph.D. Thesis. Bangi: Universiti Kebangsaan Malaysia.

Bramley. P. (1996). Evaluation of Training Effectiveness: Benchmarking Your Training Activity against Best Practice (2nd ed.). London: McGraw-Hill.

Buckley, R., \& Caple, J. (1992). The Theory and Practice of Training (2nd ed.). London: Kogan Page.

Chan, Y. F. (2004). The Effectiveness of School Management and Leadership Courses for Headmasters. Ph.D. Thesis, Serdang: Universiti Putra Malaysia.

Educational Planning and Research Division (2006). Report on Evaluation Studies Graduates of NPQH. Putrajaya: Ministry of Education

Hair, J. F., Black, W. C., Babin, B. J., Anderson, R. E., \& Tatham, R. L. (2006). Multivariate Data Analysis (6th ed.). New Jersey: Pearson Educational International.

Hashim, S., Yaakub, R., \& Ahmad, M. Z. (2007). Pedagogy-Effective Strategies and Techniques to Teach Effectively. Kuala Lumpur: PTS Professional Publishing Sdn. Bhd.

Hassan, R., Abdul Halim, R., \& Syed Iman, S. S. J. (2006). Training Program Evaluation Institute Aminuddin Baki: A Review of the Program NPQH Cohort 9/2005. National Seminar on Management and Leadership Education 13th. Institut Aminuddin Baki, KPM. Genting Highlands.

Ibrahim, M. S. (1992). An Assessment of Teacher In-Service Education in Malaysia and Its Implications for the Future. PhD Thesis, Bangi: Universiti Kebangsaan Malaysia.

Jaba, S. (2013). Availability Relationships, Acceptance, Operation and Life Skills Teacher Concerns with Integrated Agricultural Practice School Based Assessment. PhD Thesis, Jalan Upm: Universiti Putra Malaysia.

John, A. (1989). Education Staff Development. London: Biddles Ltd.

Kirkpatrick, D. L. (1959). Techniques for Evaluation Training Programs. Journal of the American Society of Training Directors, 13, 21-26.

Kirkpatrick, D. L. (1975). Evaluating Training Program. WI: American Society for Training and Development, Inc.

Kirkpatrick, D. L. (1994). Evaluating Training Program—The Four Levels. San Francisco, CA: Berret-Koehler Publishers, Inc.

Kirkpatrick, D. L. (1996). Great Ideas Revisited. Training and Development Journal, 50, 54-59.

Kirkpatrick, D. L. (2000). Evaluating Training Programs: The Four Levels-The ASTD Handbook of Training Design and Delivery. VA: The American Society of Training and Development; New York: McGraw-Hill.

Knowles, M. S. (1980). The Modern Practice of Adult Education. New York: Cambridge, The Adult Education Company.

Konting, M. M. (2002). Research Methods in Education (3rd ed.). Kuala Lumpur: Dewan Bahasa dan Pustaka.

Mansor, S. (2009). In-Service Training Report. Jitra, Kedah: Darul Aman Teacher Training Institute.

McNamara, C. (1998). Basic Guide to Program Evaluation.

https://www.google.com.my/search?q=McNamara\%2C+C.+(1998).-+Basic+Guide+to+program+evaluation

Md. Noor, A. A. (2003). An Investigation into the Headship Training Program for Aspiring Primary School Head Teachers. Doctoral Dissertation, Bristol: University of Bristol.

Mohd Asari, S. (2013). School Based Assessment for UPSR: An Evaluation towards a National Assessment System Transformation. Master Thesis, Bangi: Universiti Kebangsaan Malaysia.

Moidunny, K. (2009). National Principalship Qualification Effectiveness Program (NPQH). PhD Thesis, Bangi: Universiti Kebangsaan Malaysia.

Pallant, J. (2010). SPSS Survival Manual (4th ed.). Berksire, UK: Open University Press.

Razali, H. (2006). Effects of In-Service Training on the Quality of Teaching and Learning in the Field of Dam Engineering and Vocational. Master Thesis. Batu Pahat.: Kolej Universiti Teknologi Tun Hussein Onn.

Reeves, M. (1994). Evaluating of Training. Petaling Jaya: Pelanduk Publication (M) Sdn. Bhd.

Rodzi, A. (2012). School Based Assessment: Implementation and Challenges (The Post-Modern Perspective on Educational Needs) Internet 8.Okt.2012.

Withers, B. (2000). Basic Training: Getting Ready to Present. The ASTD Handbook of Training Design and Delivery. New York: McGraw-Hill. 


\section{Appendix: Regression Normal Plot Graph, Graph Plot Distribution Regression, Correlation Matrix}

APPENDIX A1-A3: Normal Regression Plot Graf, Graf Distribution Plot Regression, Correlation Matrix: The Independent Variable (Feedback) The Contributes to Knowledge among Teachers who attended in-service training SBA
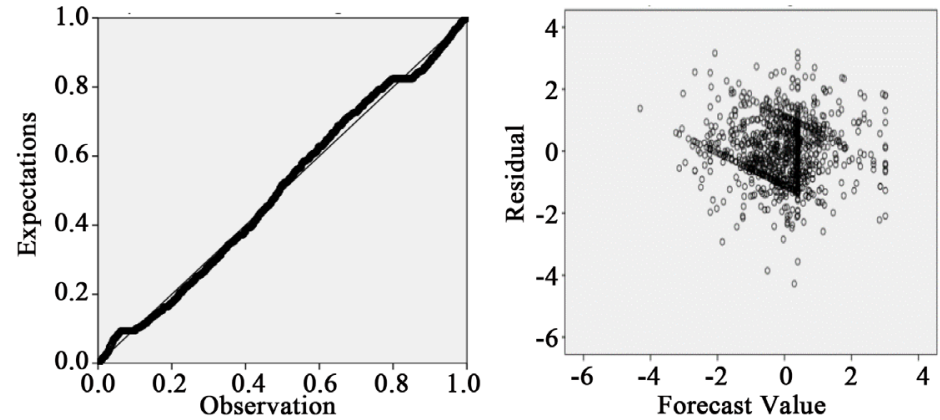

\begin{tabular}{|c|c|c|c|c|c|}
\hline & KF & BPB & BP & JUF & KU \\
\hline KF & 1.000 & .474 & .452 & .425 & .437 \\
\hline BPB & & 1.000 & .673 & .638 & .669 \\
\hline BP & & & 1.000 & .722 & .682 \\
\hline JUF & & & & 1.000 & .736 \\
\hline KU & & & & & 1.000 \\
\hline
\end{tabular}

APPENDIX A4-A6: Normal Regression Plot graph, graph Distribution Plot Regression, Correlation Matrix: The Independent Variables (reaction) that contribute to Skills Among Teachers who attended in-service training SBA
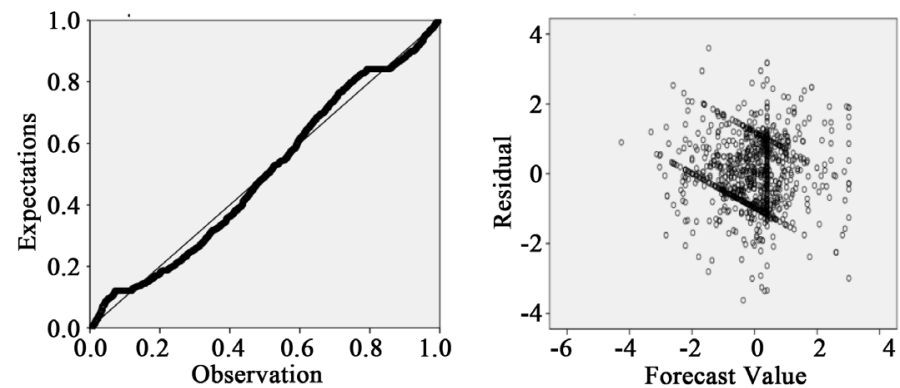

\begin{tabular}{|c|c|c|c|c|c|}
\hline & KF & BPB & BP & JUF & KU \\
\hline KF & 1.000 & .474 & .452 & .425 & .437 \\
\hline BPB & & 1.000 & .673 & .638 & .669 \\
\hline BP & & & 1.000 & .722 & .682 \\
\hline JUF & & & & 1.000 & .736 \\
\hline KU & & & & & 1.000 \\
\hline
\end{tabular}

APPENDIX A7-A9: Normal Regression Plot graph, graph Distribution Plot Regression, Correlation Matrix: The Independent Variables (reaction) Contributing to the attitude among teachers who attended in-service training SBA
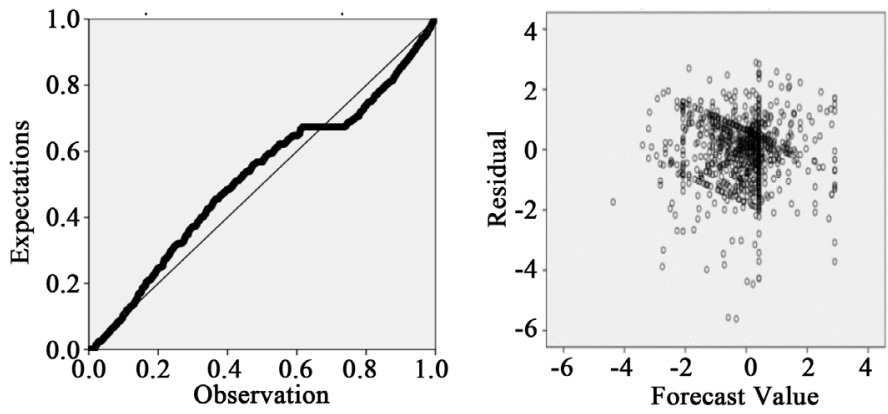

\begin{tabular}{|c|c|c|c|c|c|}
\hline & KF & BPB & BP & JUF & KU \\
\hline KF & .000 & .458 & .445 & .422 & .431 \\
\hline BPB & & 1.000 & .686 & .644 & .669 \\
\hline BP & & & 1.000 & .733 & .700 \\
\hline JUF & & & & 1.000 & .733 \\
\hline KU & & & & & 1.000 \\
\hline
\end{tabular}

KU: Content; KF: physical facilities; BPB: instructional materials; BP: teaching materials; JUF: Coaches/Fasilitator. 